in successive crops for a week or more but rarely after the first month of life.

Prognosis.-The general prognosis of the disease is unfavourable. The mortality of Ritter's cases was 48.82 per cent. The cause of death in some cases is the intensity of the attack ; in others it is exhaustion, secondary septicæmia, marasmus or loss of animal heat. Inanition is a frequent cause, as is also the development of some secondary and complicating disease.

Treatment.-The vital powers of the infant shonld be sustained by proper nourishment and tonics should be administered. Externally fats and oils, with some antiseptic such as boric acid, resorcin, or ichthyol, are recommended, as well as the enveloping of the patient in wadding or in absorbent cotton. Ichthyol being a parasiticide and also a keratoplastic agent would be peculiarly indicated.

Calcutta.

\section{SIX CASES OF OPERATION FOR APPENDICITIS.}

BY HORATIO P. SYMONDS,

SLRGEOY TO THE RADCLITFE INFIRMART, OXFORD.

THE following series of consecutive cases of operation for appendicitis have been under my care in private practice during the last few years.

CASE 1.-A young man, aged 21 years, was first seen by me in February, 1896, when he was suffering from an acute attack of appendicitis. - There were pain in the right iliac region, an irregular temperature, and constipation. There was also a feeling of resistance in the same region and dulness the extent of which varied considerably. This dulness was no doubt due to a fæcal accumulation in the cæcum, for when the bowels were relieved it disappeared almost immediately. The treatment which $I$ prescribed was rest in bed, a slop diet, small and frequent doses of saline aperients, and soap-and-water enemata. The acute stage of the attack lasted a week, when the symptoms gradually subsided. The patient remained well for some months but had a similar attack in the month of July while he was away from Oxford. In November another attack of a similar character occurred and I advised that when it quieted down the appendix should be removed. The patient consented to this and the operation was performed on Nov. 24th. A curved incision was made about an inch internal to Poupart's ligament, commencing a little above the level of the anterior superior iliac spine. After some little exploration the appendix was found lying in a number of not very firm adhesions below and behind the cæcum. It was ligatured off as close to its origin as was possible and removed. In it was a small calculus which was on the point of ulcerating through. The patient made an uninterrupted recovery and has been in good health ever since.

CASE 2.-A man, aged 25 years, suffered in November, 1897, from a slight attack of appendicitis, with pain, high temperature, and constipation. The condition, however, passed off in a few days. Realising the danger which he ran he himself raised the question of operation and he determined to have the appendix removed. This was done on Jan. 17th, 1898, when an incision was made as in Case 1 and the abdominal cavity opened. The appendix was easily found lying free behind the cæcum. There were no adhesions. The peritoneal covering was much inflamed, evidently from the remains of the acute attack, and the terminal inch of the organ was tensely distended. A constriction existed so close to the crcum that it was difficul to get a stump to ligature and therefore the appendix had to be cut very close to the bowel. What stump was left had a circular ligature applied to it and in addition the mucous membrane was invaginated and the two peritoneal surfaces thus brought into contact were sewn to each other, the principle being practically that of Lembert's sutures. The external wound was stitched up in the usual way. The patient made an uninterrupted recovery and has since remained quite well.

CASE 3.-A man, aged about 38 years, was seen by me on Feb. 19th, 1899, suffering from pain in the right iliac region, sickness, and constipation of two or three days' duration. The temperature on that day ranged about $104^{\circ} \mathrm{F}$. and a distinct swelling was present in the region of the pain. The patient was very ill and on the following day was very much worse, all the symptoms being aggravated and the condition of the gravest description. An operation was therefore undertaken. An incision in the same situation as that in the two previous cases was made and an abscess containing a large quantity of foetid pus was evacuated. It was apparently incompletely cut off from the general peritoneal cavity, coils of bowel covered by recent lymph presenting at the wound. It was not considered advisable to explore for the vermiform appendix and the latter was therefore not seen. Two drainage-tubes were inserted into the abscess cavity which was douched out with sterile boric acid solution. The patient was very much collapsed after the operation and for some hours was in a most critical state. The wound was repeatedly dressed and douched with warm boric lotion. For several days the condition of the patient was most serious, but about the third day the temperature, which all through varied between $102^{\circ}$ and $104^{\circ}$, began to fall and gradually returned to the normal. The bowels were relieved by small doses of salines repeated every two hours till an action took place. During recovery a piece of small intestine persistently protruded from the wound and all attempts by graduated compresses, \&c., failed to maintain it in position within the abdominal cavity. A few weeks after convalescence had been established a small fæcal fistula formed in it. An operation was undertaken for the relief of this. The knuckle of gut concerned was freed from its adhesions to the anterior abdominal wall. The edges of the fistula were invaginated and sewn over, the skin wound being again sewn over this. Recovery was now uninterrupted and the patient is now quite well.

CASE 4.-A strong, healthy, young farmer was seen by me in consultation on Sept. 11th, 1898. On the 8th, four days previously, he had had a long day's shooting and was extremely fatigued. During that night he began to feel great pain in the right iliac region and on the following day he was seen by his medical adviser who found him suffering from pain, sickness, considerable fever, and constipation. He continued getting worse during the next 48 hours and a swelling also appeared in the right iliac fossa. Agreeing with the diagnosis of vermiform mischief with abscess formation I recommended operation which was performed on Sept. 11th. On cutting down over the swelling an abscess was opened which contained a large quantity of foulsmelling discharge. With some difficulty the appendix was found. It was in a state of intense inflammation amounting almost to necrosis and was on the point of rupturing. It was removed. Two indiarubber tubes were placed in the abscess carity and the wound was partially stitched up. Although at the time of operation the patient was in a very serious condition he began to improve from the moment it was completed. The pain disappeared and the general condition became better. The wound was douched every four hours. The temperature commenced to fall very shortly after the conclusion of the operation. A piece of intestine presented at the wound and gave some trouble subsequently, but it was finally retained in position by the application of a deep suture. About three weeks after the operation the patient suffered from slight dry pleurisy on the right side which, however, became quiescent, though he continually complained of slight pain in the side and had a short hacking cough. Towards the end of October the temperature began to rise a little towards evening and it was then found that effusion was taking place into the right pleural cavity. The temperature continuing to go up an exploratory aspiration disclosed the existence of an empyema. This was therefore evacuated on Nov. 1st and a large quantity of pus was evacuated. To admit of better expansion of the lung portions of ribs were removed. The recovery from this empyema was tedious in consequence of the tendency of the cavity to fill up in pouches with pus, but ultimately complete closure of the wound took place and the patient is now quite well.

CASE 5.-A woman, aged about 40 years, was seen by me in consultation in October, 1898, suffering from pain in the right iliac region, slight fever, and constipation. I diagnosed vermiform inflammation and recommended removal of the appendix. The abdomen was opened by the usual incision and the appendix was easily found. There were no adhesions and the appendix was removed as in Case 2. The patient made an uninterrupted recovery.

CASE 6.-A young woman had had four slight attacks of appendicitis and as their constant recurrence was a source 
of great trouble she consented to the removal of the appendix. This was done in June, 1899. The incision was the same as in Case 5. The appendix was easily found. There were no adhesions and it was removed in the manner already described. It was inflamed externally and outside and was decidedly distended with a purulent fluid. The patient made an uninterrupted recovery.

Remarks.-Looking at these cases as a series it can be said that in two of them (Case 3 and Case 4) the condition of the patient at the time of the operation was of the gravest possible nature and a fatal issue was merely a question of time. In Case 1 the chief point was the difficulty of finding the appendix, bound up as it was in a mass of adhesions. Here the presence of a calculus just ulcerating through was a gave menace to the patient's safety. The other cases illustrate a not unimportant point-viz., that attacks of appendicitis may occur without any great inflammation taking place in the surrounding peritoneum. The inflammatory change in these is probably chiefly found in the mucous tissue. The occurrence of a stenosis such as existed in Case 2 paves the way for a damming up of the secretions and for the occurrence of the necrotic change which is frequently seen in fatal cases without much suppuration. I believe that in slight cases of appendicitis, when one or several attacks have occurred, the right course is to recommend removal of the offending organ. It is usually found quite easily and ought to be ligatured as near its origin as possible, a circular ligature being first applied. The cut mucous membrance ought to be carefully swabbed with a 1 in 20 carbolic acid solution and then be invaginated, peritoneal surface being sewn to peritoneal surface. In cases where adhesions are present great judgment is required and no rules can be laid down for the guidance of the surgeon. In sewing up the abdominal wound in these simple cases it is needless to say that the muscular and especially the aponeurotic coats ought to be sewn up with deep sutures. In suppurative cases the cardinal point is never to delay an hour more than is absolutely necessary before operating. In such cases I never give morphia or other sedatives which may mask symptoms. In cutting down I go straight for the most prominent part of the inflammatory tumour. Once the abscess is found and evacuated unless the vermiform appendix is found at once I do not seek for it. With regard to the after treatment of these severe cases, I believe in putting in two indiarubber drainage-tubes and douching out the cavity with boiled water every few hours night and day for 48 hours. All the cases I have recorded have been inmates of the Sarah Acland Home in this city, where the arrangements of nursing, \&c., are of the best description.

Oxford.

\section{TWO CASES OF SEVERE SUBCUTANEOUS INJURY TO THE PERONEAL NERVE; OPERATION.}

BY R. G. HOGARTH, F.R.C.S. ENG.,

SURGEON TO THE SAMARITAN HOSPITAL FOR WOMEN, NOTTINGHAM.

CASE 1.-A man, aged 29 years, received a very violent blow either from a kick or from a collision whilst playing football, the brunt of which fell over the head of the left fibula and outer side of the left knee. There were intense pain and inability to stand. There was no fracture. The extensor muscles of the toes and flexors of the ankle were completely paralysed and there was anæsthesia of the skin of the dorsum of the toes and foot and for some distance up the front of the leg. The anæsthesia was complete in the cleft between the big toe and the second toe, but only blunted in the other parts. This is interesting and was no doubt due to the high division of the nerve (which was found at the operation which took place subsequently). A large sub. cutaneous extravasation of blood formed which extended half way up the thigh and filled the popliteal space and reached downwards as far as the ankle. On pressing the skin over the head of the fibula the blood was displaced and the finger seemed to come down immediately on the bone, just as if there was no intervening tissue between the bone and the skin. The skin was quite intact. There was some effusion into the knee-joint. The leg was treated on a back splint with lead and opium lotion on lint covered with oil silk and the use of considerable pressure by bandaging firmly over cotton-wool to prevent further extravasation of blood. In spite of this the extravasation was very extensive. At the end of a month the splint having been discarded and most of the swelling having gone the patient could move about a little. The anzesthesia and paralysis of the muscles remained the same. His foot when lifted from the ground hung in a position of talipes equinus with slight varus and his toes caught in the ground when he walked. At this time (one month after the injury) all the paralysed muscles-viz., the tibialis anticus, the extensor longus digitorum, the peroneus longus, the peroneus brevis, the peroneus tertius, the extensor longus hallucis, and the extensor brevis digitorumshowed when tested carefully with an electric battery marked reaction of degeneration. None of them responded to the faradaic current. There was slightly increased irritability to the galvanic current and there were marked polar changes. The muscles were then thoroughly massaged and galvanised every day. At the end of a month of this treatment-that is, two months from the time of the injury - there was no improvement. The degeneration in the paralysed muscles was more marked and there was considerable wasting. There was no thickening now to be felt over the seat of the injury. The patient was advised to have the nerve exposed so as to ascertain its condition and to rectify it if possible. He refused to have this done and went to London for treatment. At the end of another month he returned in the same condition and asked for the operation. It was pointed out to him that he was not so likely now to derive benefit from the operation as he had delayed so long.

Operation (three months after the injury).-An incision nine inches long was made, commencing in the popliteal space on the inner side of the tendon of the biceps and continued downwards in the course of the nerve round the head of the fibula. The nerve was found to be free at the lower end of the wound and was carefully traced up. It was embedded in dense cicatricial tissue round the head of the fibula to which it was intimately adberent. At the npper end the nerve was glued by adhesions to the tendon of the biceps. Altogether it was implicated for about four inches. The nerve divided very high up just before leaving the popliteal space and the anterior tibial branch was the one most involved, which accounted for the complete anæsthesia between the big and second tces. In some places it was almost impossible to distinguish nerve from fibrous tissue. Had it only been involved for a short distance it would undoubtedly have been best to have removed the piece of nerve and to have united the ends. In this case it was out of the question as the ends could not have been approximated. It was accordingly thoroughly freed. The wound was dressed and in a week it healed. Within 12 hours the skin supplied by the nerve and the anæsthetised area which had previously keen cold and bluish were warm and red and sensation was beginning to return. Daily massage and galvanism of the muscles were commenced as soon as possible. The muscles were slow to begin improving but they did so almost imperceptibly and at the end of three months the patient could flex his foot to a right angle and could walk and run without any lameness. The muscles filled out and at the end of three months the patient had gained two and a half inches in measurement round the calf. Of course, part of the wasting was due to disease. Sensibility had returned completely in a month. He has not been seen since then.

CASE 2.-A man, aged 19 years, had received a severe kick on the posterior and outer part of the left knee, principally over the tendon of the biceps. He dropped to the ground at once and the feeling went from his foot and he was in great pain. He was laid up for 10 days and was attended by a medical practitioner. When he got up his foot dropped and his toes caught in the ground when he walked. He consulted another practitioner and massage was ordered. Later he saw a bone-setter who, saying that a small cartilage was out in his knee, wrenched it. This produced synovitis. He was seen shortly afterwards-i.e., two months after the injury. He bad all the signs and symptoms which were observed in the other case except that the anæsthesia was not so complete and that in addition he had synovitis of the knee. His foot hung in the equinus position with a slight tendency to varus. The electrical reaction of the muscles showed marked reaction of 